\title{
Gastrointestinal bleeding after endoscopic ultrasound-guided gallbladder drainage
}

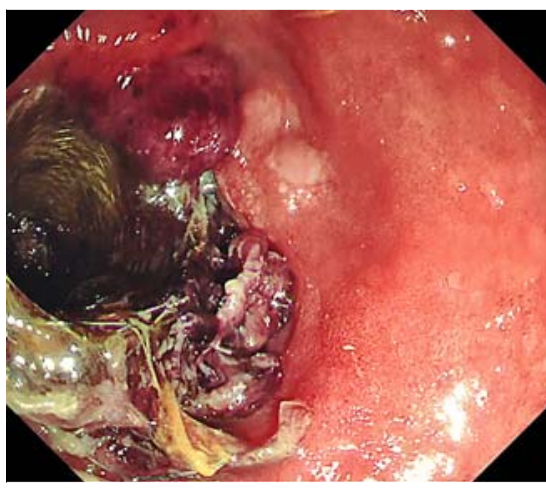

- Fig. 1 Endoscopic image showing the lumen-apposing metal stent remaining in situ in the duodenum but having caused erosion with ulceration and bleeding.

Endoscopic ultrasound (EUS)-guided gallbladder drainage (EGBD) is gaining popularity as an option for the treatment of acute cholecystitis in patients who would be considered high risk for cholecystectomy [1]. EGBD has been shown to be associated with comparable technical and clinical success rates to percutaneous cholecystostomy, whilst carrying a $4.8 \%-22 \%$ risk of adverse events, including pneumoperitoneum, bile leak, and stent migration [2-5]. Stent-induced bleeding after EGBD is however uncommon.

A 95-year-old men on dabigatran with multiple comorbidities suffered from acute cholecystitis. As he was high risk for cholecystectomy, EGBD was performed. A lumen-apposing metal stent (LAMS; Spaxus, Taewoong Medical Corporation, South Korea) and a 3-cm double-pigtail stent were inserted for gallbladder drainage. He was scheduled for cholecystoscopy and stone removal 1 month later. On cholecystoscopy, a 2-cm gallstone was noted at Hartmann's pouch but could not be removed, so the LAMS was left in situ as a long-term stent. After 4 months, he was admitted with hematemesis and tarry stools; his hemoglobin had dropped to $5.9 \mathrm{~g} / \mathrm{dL}$. An urgent endoscopy was performed and it

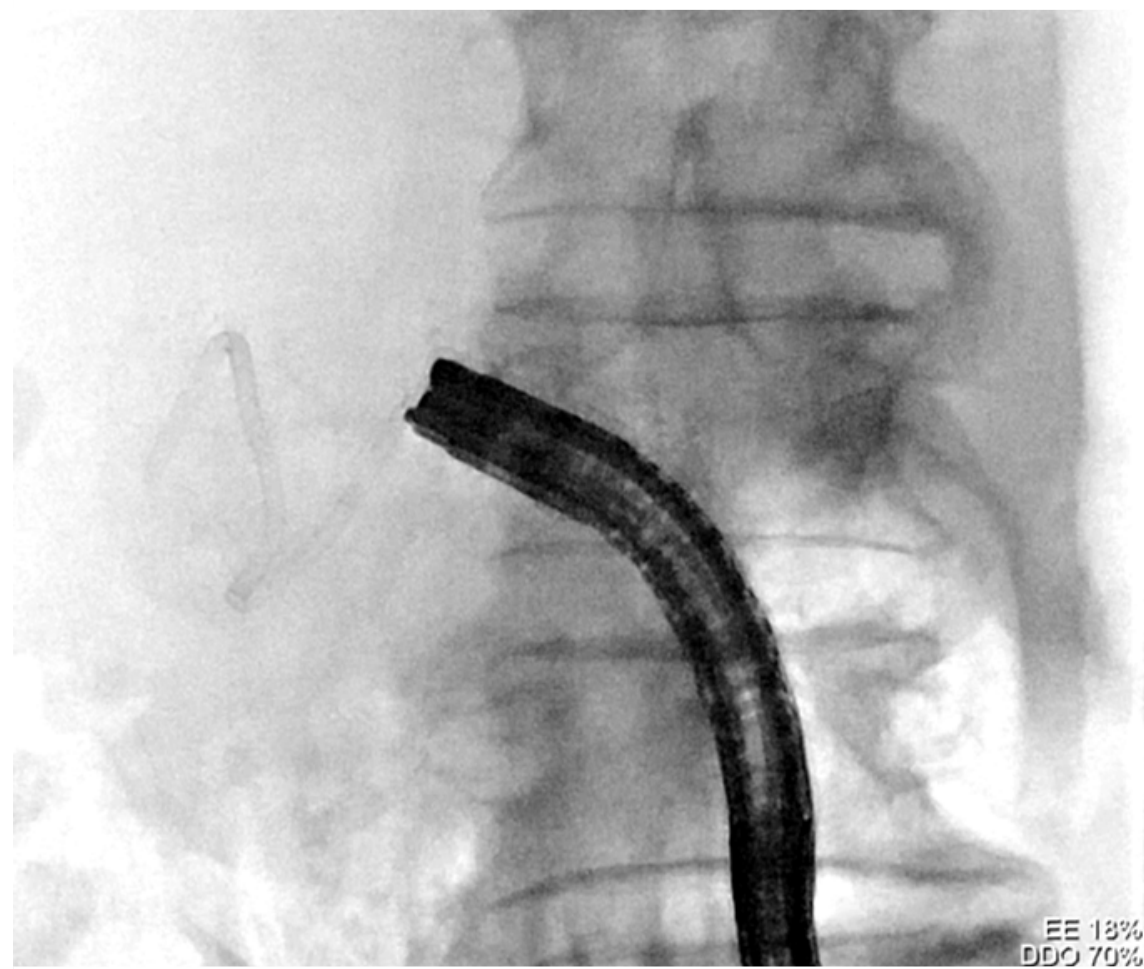

- Fig. 2 Fluoroscopic image showing the lumen-apposing metal stent exchanged with a double-pigtail plastic stent.
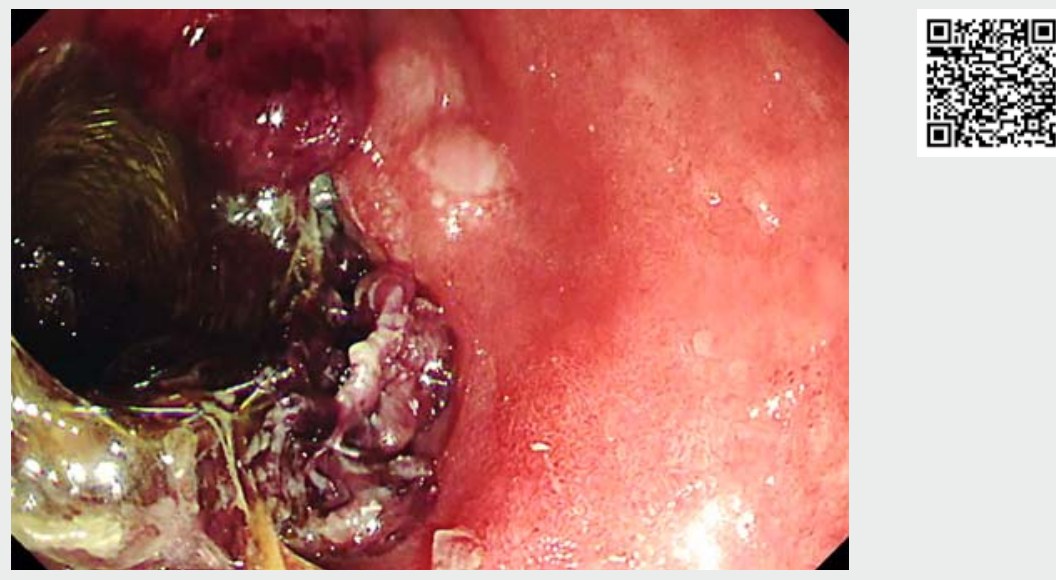

V Video 1 Endoscopy performed in a patient with gastrointestinal bleeding after endoscopic ultrasound-guided gallbladder drainage.

was found that his stomach was filled with blood clots ( $\vee$ Video 1 ). The LAMS remained in situ at the inferoposterior wall of the first part of the duodenum, 
but it had caused erosion with ulceration and bleeding ( $>$ Fig. 1 ). The stent was removed and exchanged for a double-pigtail stent to maintain drainage of the gallbladder (> Fig.2). Hemostatic treatment was not required. The patient's dabigatran was stopped and was not restarted. His condition stabilized and he was discharged 6 days later.

Stent-induced gastrointestinal bleeding has to be considered in post-EGBD patients with anemia or signs of gastrointestinal bleeding. Further studies on the safety of anticoagulant use in patients planned for long-term stenting are required.

Endoscopy_UCTN_Code_TTT_1AS_2AG

\section{Competing interests}

Prof. Anthony Y. B. Teoh is a consultant for Boston Scientific, Cook, Taewoong, and Microtech Medical Corporations.

The authors

Erica On Ting Chan, Shannon Melissa Chan, Hon Chi Yip, Anthony Yuen Bun Teoh Department of Surgery, Prince of Wales Hospital, The Chinese University of Hong Kong, Shatin, Hong Kong
Corresponding author

\section{Prof. Anthony Y. B. Teoh, MD}

Department of Surgery, Prince of Wales Hospital, Shatin, New Territories, Hong Kong SAR

Fax: +852-35057974

anthonyteoh@surgery.cuhk.edu.hk

\section{References}

[1] Luk SW, Irani S, Krishnamoorthi R et al. Endoscopic ultrasound-guided gallbladder drainage versus percutaneous cholecystostomy for high risk surgical patients with acute cholecystitis: a systematic review and meta-analysis. Endoscopy 2019; 51: 722 773

[2] Teoh AY, Serna C, Penas I et al. Endoscopic ultrasound-guided gallbladder drainage reduces adverse events compared with percutaneous cholecystostomy in patients who are unfit for cholecystectomy. Endoscopy 2017; 49: 130-138

[3] Tyberg A, Saumoy M, Sequeiros EV et al. EUS-guided versus percutaneous gallbladder drainage: isn't it time to convert? J Clin Gastroenterol 2018; 52: 79-84

[4] Irani S, Ngamruengphong S, Teoh A et al. Similar efficacies of endoscopic ultrasound gallbladder drainage with a lumen-apposing metal stent versus percutaneous transhepatic gallbladder drainage for acute cholecystitis. Clin Gastroenterol Hepatol 2017; 15: 738-745
[5] Choi JH, Kim HW, Lee JC et al. Percutaneous transhepatic versus EUS-guided gallbladder drainage for malignant cystic duct obstruction. Gastrointest Endosc 2017; 85: 357364

Bibliography

DOI https://doi.org/10.1055/a-1089-7479

Published online: 29.1.2020

Endoscopy 2020; 52: E249-E250

(c) Georg Thieme Verlag KG

Stuttgart · New York

ISSN 0013-726X

\section{ENDOSCOPY E-VIDEOS}

https://eref.thieme.de/e-videos

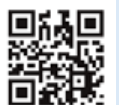

Endoscopy E-Videos is a free access online section, reporting on interesting cases and new techniques in gastroenterological endoscopy. All papers include a high quality video and all contributions are freely accessible online.

This section has its own submission website at

https://mc.manuscriptcentral.com/e-videos 